\title{
Characterization of ceramic components fabricated using binder jetting additive manufacturing technology
}

\author{
J. A. Gonzalez ${ }^{12}$, J. Mireles ${ }^{1,3}$, Y. Lin $^{3}$, R. B. Wicker ${ }^{1,3}$ \\ 1 W.M. Keck Center for 3D Innovation, The University of Texas at El Paso, El Paso, TX 79968, USA \\ 2 Department of Metallurgical and Materials Engineering, The University of Texas at El Paso, El \\ Paso, TX 79968, USA \\ 3Department of Mechanical Engineering, The University of Texas at El Paso, TX 79968, USA
}

\begin{abstract}
Binder jetting additive manufacturing is an emerging technology with capability of processing a wide range of commercial materials, including metals and ceramics (316 SS, $420 \mathrm{SS}$, Inconel 625, Iron, Silica). In this project, aluminum oxide $\left(\mathrm{Al}_{2} \mathrm{O}_{3}\right)$ powder was used for part fabrication. Various build parameters (e.g. layer thickness, saturation, particle size) were modified and different sintering profiles were investigated to achieve nearly full-density parts ( $96 \%)$. The material's microstructure and physical properties were characterized. Full XRD, compression testing, and dielectric testing were conducted on all parts. Sintered alumina parts were achieved with an average compressive strength of $131.86 \mathrm{MPa}(16$ hours sintering profile) and a dielectric constant of 9.47 to 5.65 forafrequencyrangeof $20 \mathrm{~Hz}$ to $1 \mathrm{MHz}$. The complexityoffered by additive processing aluminum oxide can be extended to the manufacturing of high value energy and environmental components for environmental systems (e.g. filters and membranes) or biomedical implants with integrated reticulated structures for improved osseointegration.
\end{abstract}

\section{Introduction}

Fabrication of ceramics in the macro scale is difficult due to their brittle and hard nature, especially when producing complex geometries of fired ceramics. Ceramics, in general, have a wide range of applications ranging from biomedical implants to engine components in the aerospace and automotive industry(Doore and Hubner 1984). In this research, alumina was selected for fabrication because of its wide applicability in industries such as electronic, biomedical, and aerospace. Alumina isa high-temperature ceramic that provides stable electrical properties and mechanical robustness (Tan, et al. 2014), it is also a structural ceramic due to its wear resistant propertiesand itsability to withstand severe mechanical stresses in corrosive and thermal environments (Medvedovski, Alumina-mullite ceramics for structural applications 2006). In addition, alumina is catalogued as a versatile ceramic due to the wide variety of applications as a dielectric material, optical (when transparent and used in transparent envelopes in street lamps), biomedical (hip implants) and thermal (packages for integrated circuits). Some of its main properties are stability at high temperatures, permeability, high surface area and thermal shock resistance (Biasini, Parasporo and Bellosi 1997). Alumina can be present as $\alpha, \gamma$ and $\beta$ phases, being $\alpha-$ alumina present in ambient atmospheres, which has an hexagonal closed packed structure, with a melting point of $2054^{\circ} \mathrm{C}$ and a hardness equal to 9 on the Mohs scale (Meethong, Sirirot and Srilomsak 2013). Advantages of this ceramic in traditional manufacturing are its low cost and ease of fabrication by slip casting, pressing, and injection molding(Medvedovski, Ballistic performance of armour ceramics: Influence of design and structure. Part I 2010). Machining of alumina ceramics can be expensive due to the level of experience required and material waste that can be generated during the process (Leu, Pattnaik and Hilmas 2010). It is important to note that alumina has a wide range of purity that depends on the amount of elements such as Silicon within the alloy. High purity alumina ( $>95 \%)$ is typically used for high voltage electrical substrates and insulation while low purity alumina ( $60-85 \%)$ is primarily used for temperature resistance. In this research low purity alumina precursor powder was used to demonstrate the fabrication of alumina using binder jetting additive manufacturing technology.

Additive manufacturing (AM), or the method of creating a three-dimensional object through a layer-by-layer process, has been widely researched for its potentialto process ceramics. One method that has been extensively investigated is Fused Deposition of Ceramics (FDC), developed by Rutgers University(Allahverdi, et al. 2001). This process is based on a material extrusion method used to fabricate 
polymers. In order to process conventional ceramics, such as $\mathrm{SiO}_{2}, \mathrm{Si}_{3} \mathrm{~N}_{4}, \mathrm{Al}_{2} \mathrm{O}_{3}$, lead zirconium titanate (PZT), the development of organic binders, binder removal techniques, and sintering conditions have been developed (Agarwala, et al. 1996).In a study conducted by Allahverdiet al., alumina structures with photonic bandgap structures were fabricated with the use of wax as support material (Allahverdi, et al. 2001).Laser Engineered Net Shaping (LENS) has been used to fabricate $\alpha-\mathrm{Al}_{2} \mathrm{O}_{3}$ in different shapes such as cylinders, cubes and gears. Compressive testing results showed anisotropic properties that could not be altered by heat treatment(Balla, Bose and Bandyopadhyay 2008).By having a mixture of resin and ceramic where a slurry containing alumina powder and a UV curable monomer, among other things, provided the necessary means to fabricate three dimensional parts by stereolitography(Hinczewski, Corbel and Chartier 1998)(Kruth, Leu and Nakagawa 1998). In addition, by adding alumina particles to create colloidal ink, direct ink-jet printing of ceramics was achieved by Lewis in 2002 to provide tailored properties (Lewis 2002). In this research, binder-jetting technology was used as a means for fabrication. Binder jetting technology is a powder bed based technology that selectively deposits a binder layer-bylayer onto a powder bed to create a three-dimensional object. Upon fabrication, a green body is obtained which undergoes a heat treatment cycle that burns out the binder and sinters the powder particles. The goal of this research was to study the feasibility of fabricating ceramic structures that can be used as packages for sensors or electronics exposed to high temperature environments.

\section{Materials and methods}

\subsection{Fabrication}

Fabrication was achieved by the binder jetting process using the ExOne M-Lab system (Irwin, PA serial number: $0600 \mathrm{H} 2$ ). The process consists of fabricating three-dimensional parts (previously designed by computer-aided design (CAD) and uploaded in the system as $\mathrm{a}^{6}$.stl' file) from powder precursor material. Powders are bonded together in a layer-by-layer fashion. The ExOne M-Lab printer consists of a two-bed system (as shown in Figure 1); one bed is for the base powder material and the other for part fabrication. Powder layers are spread with a roller while the bed is mechanically moving in the Xdirection. Once the powder layer is uniformly spread, the powder bed returns to its original position where binder droplets are selectively deposited through apiezoelectricprinthead for part fabrication. Once the binder is deposited, the powder bed moves below the heater, where heat is provided for a set amount of time to achieve powder binding. This is considered as the fabrication of one layer (one full cycle), and the process continues until part fabrication is complete.

For this project, a 1.75:1 ratio of powder and binder deposition was used, which means that the equivalence of one layer and three fourths of a layer of powder from the powder bed (feed) are used to fabricate one layer in the build bed to achieve better powder packing. Based on successful results described elsewhere (Gaytan, et al. 2013) fabrication of $\mathrm{Al}_{2} \mathrm{O}_{3}$ parts was performed using binder saturation of $60 \%$ and various layer thicknesses. The layer thickness was determined based on the particle size of the powder that was being used.Three different powders were used for fabrication and three layer thickness parameters were used for each powder. The first layer thickness that was used corresponded to the particle size. Then half the particle size and double the particle size were used as the layer thickness to determine its influence on final sample property. After the select layer thicknesses were used for all the powders, the powders were combined and mixed evenly to achieve a large distribution of particle size, in order to determine if the density could be improved. For the mixed powders, the range of layer thickness depended on using the largest, median, and the smallest used on the pervious runs. Based on the amount of empty space that is present due to the packing of the powder during each layer, the binder will replace such space in order to remove any empty space. After fabrication is finished, the building envelope is placed in the oven at $195^{\circ} \mathrm{C}$ for 2 hours. This step is performed to cure the binder selectively placed in the fabricated part, allowing the separation of the fabricated geometry from the unbound powder. After the binder is cured, the parts are brushed to remove unbound powder and prepared for sintering. 


\subsection{Powder}

Aluminum oxide grinding powder purchased from Ted Pella, Inc. was used for the fabrication process. Three different grits were used in order to determine the effect of particle size on build quality (e.g. density). The three different grits used were 240, 320, and400. Note that the grit size is related to particle size where 240 grit is 53 microns, 320 grit is 45 microns, and 400 grit to 30 microns.

\subsection{Sintering Profile}

Two different schemes of sintering time and temperature were used in order to determine how the shrinkage and density would change. The furnace used for sintering was a Rapid Temp Model 1710 FL Laboratory Box Furnace by CM Furnace Inc. The highest temperature that was reached for both sintering profiles was kept consistent at $1600^{\circ} \mathrm{C}$. The heating rate that was used was $10^{\circ} \mathrm{C}$ per minute, and parts were sintered in atmospheric pressure with no other gas being introduced during the process. The part wassintered attwo different dwell durations: 2 hours and16 hours.

\subsection{Characterization}

Characterization of shrinkage was defined by the change in part dimensionscaused by the sintering. That is, by sintering voided space will be filled by surrounding particles that diffusion and bond with one another, which will reduced the overall geometry of an object. The two different sintering profiles were reviewed experimentally to compare the shrinkage percentage in $\mathrm{X}, \mathrm{Y}$ and $\mathrm{Z}$ dimensions. The original dimensions of the samples were set by the CAD file to be $20 \mathrm{~mm}, 25 \mathrm{~mm}, 10 \mathrm{~mm}$ as seen in Figure 2. Green bodies were measured using caliper, and re-measured after sintering (Figure 3 ).

Parts selected for characterization with the use of scanning electron microscope were sputtercoated with gold and palladium (Gatan Precision Etching Coating System Model 682) for 1 minute, at a current of $300 \mathrm{~mA}$, and vacuum of $10^{-6}$ Torr. The morphology and sintering of particles in the specimens were examined using a scanning electron microscope (Hitachi S-4800: Field Emission SEM, Hitachi High Technologies America Inc., Dallas, Texas). A Bruker X-ray diffractometer was usedto confirm the phases present in sintered parts and un-sintered powder. X-ray diffraction is based on elastic scattering, which generates intensity peaks characteristic of orientation and phases present in the analyzed sample(Cullity 1976). The slit size on the controller side was one of $8 \mathrm{~mm}$, and of $0.6 \mathrm{~mm}$ on the tube side. The scan range ( $2 \theta$ values) started at $20^{\circ}$ and ended at $90^{\circ}$. The scan was performed in increment of $0.05^{\circ}$ at a speed of $0.05^{\circ} / \mathrm{min}$ to obtain very distinct intensity peaks and simplify phase and orientation detection.

\section{Results}

\subsection{Density}

The apparent density was calculated using the Archimedes' method. Here, the product of the average air and the density of water is computed and divided by the difference of the average air and average water measurements. The theoretical density of the alumina used to compare with the fabricated parts was $3.95 \mathrm{~g} / \mathrm{cm}^{3}$. Relative density was determined to quantify the amount of sintering that was done by each sintering profile. Note that sintering and density are relatedto the phenomena during thesintering process that causes powder particles to diffuse together, which causes voids to be filled by bulk material, thusideally decreasing porosity and increasing density. The graphs that are represented in Figure 4demonstrate how the density was affected with the change of layer thickness betweenthe two sintering profiles. A typical trend shows that the highest density was achieved by the smallest layer thickness using the mixed powders where therelative density was $96.51 \%$. The lowest density calculated was using the 240 grit powder size, which only averaged $64 \%$. 


\subsection{Shrinkage}

Shrinkage was experienced on all directions. On average, samples shrunk the most on the Z direction, that being $10.27 \%$ from green body dimensions. The $X$ direction had $7.92 \%$ shrinkage and $8.34 \%$ in the $\mathrm{Y}$ direction. Standard deviation was calculated for all values, where 4.99 for the $\mathrm{X}$ direction, 5.49 in the $\mathrm{Y}$ direction, and 6.39 in the $\mathrm{Z}$ direction (Table 1). The minimum amount of shrinkage occurred on the samples with the lowest density values. Samples fabricated with 240 grit powder size experienced the lowest amount of shrinkage with the part only shrinking $1.07 \%$ in the $\mathrm{X}$ direction, $1.73 \%$ in the $\mathrm{Y}$ direction, and $0.62 \%$ in the $\mathrm{Z}$ direction. The maximum amount of shrinkage was on samples fabricated with the mixed powder at $45 \mu \mathrm{m}$ layer thickness. The shrinkage experience on these samples was $8.75 \%$ in the $\mathrm{X}$ direction, $10.92 \%$ in the $\mathrm{Y}$ directions, and $15.37 \%$ in the $\mathrm{Z}$ direction.

\subsection{SEM Analysis}

Virgin powder, a green body obtained after the binder jetting process, a part exposed to a 2-hour sintering cycle, and a part exposed to a 16-hour sintering cyclewasanalyzed under a scanning electron microscope (SEM).According to the images in Figure 5 (a) and (b), there is a minimal difference between virgin powder and a green body after fabrication was completed. It appears that the alumina particles have a random morphology between them, where the packing of particles is completed by the fabrication process. After sintering is completed, the fusion of particle is visible; however pores or voids are still visible. Figure 5 (C) shows how the surface of the 2-hour sintering appears, where (D) shows less visible pores thatareconsistent with higher density measurements. Higher magnification was conducted on the part exposed to a 16-hour sintering cycle, where neck formation between two particles is visible (Figure $6)$, which is ideal when powdered materials are fully sintered.

\subsection{XRD}

The XRD intensity peaks for virgin alumina powder were compared to its sintered counterparts.Figure 7 shows alumina powder peaks obtained for both as-fabricated and sintered parts. The XRD analysis concludes that thepowder has amonoclinic crystal structure. This structure is retained when the pure alumina was sintered. Figure 7identifies the crystallographic orientations of the matched intensity peaks. According to Chang, et al, the peaks that were identified for the purchased powder aligns with the alumina peaks that indicate that the peaks appear to be $\alpha-\mathrm{Al}_{2} \mathrm{O}_{3}$.(Chang, et al. 2009)

\subsection{Compression Testing}

Compression testing was performed on the mixed powder parts for parts exposed to both sintering profiles. A comparable strength valued was obtained fromtraditionally fabricated alumina. An MTS Landmark servohydraulic test system (Eden Prairie, MN) was used to perform the compression testing.ASTM standard C773-88 was used for the design of the compression test, however the strain rate was altered from $45 \mathrm{kN} /$ per to $0.5 \mathrm{~mm} / \mathrm{min}$. The average area of the test samples was $32.23 \mathrm{~mm}^{2}$, and lengthwas $11.84 \mathrm{~mm}$. Figure 8 are the stress-strain curves for the compression test that were conducted samples both sintered at 2 hours and 16 hours. The samples that were sintered for 16 hours began to break at an average stress of $131.86 \mathrm{MPa}$, with the highest stress reached being $146.60 \mathrm{MPa}$ before fracture. Samples sintered for 2 hours were averaging $71.79 \mathrm{MPa}$ before the samples began to crack, and the higheststress reached was77.86 MPa. By sintering the parts for 16 hours, an increase in $82.98 \%$ stress was achieved when compared to parts sintered for only 2 hours. 


\subsection{Hardness}

A Hyditron TI $750 \mathrm{H}$ Ubi depth-sensing indenter was used to quantify mechanical properties in the nanoscale. Parts fabricated using the mixed powder for both sintering profiles were measured along with a green body. The green body alumina was too weak to provide any type of reading capacities. A range of data measurements was performed on all samples and averaged respectively. Parts exposed to a 2 hour sintering cycle resulted in a Young's modulus of $31.25 \mathrm{GPa}(+/-8.43 \mathrm{GPa})$ and a hardness of 240 $\mathrm{MPa}(+/-66 \mathrm{MPa})$. Parts exposed to a 16hour sintering cycle resulted in a young's modulus of $54.14 \mathrm{GPa}$ $(+/-14.54 \mathrm{GPa})$ and a hardness of $1.51 \mathrm{GPa}(+/-0.0967 \mathrm{GPa})$.Figiel, et al, calculated that a pore-free alumina young's modulus value is $379 \mathrm{GPa}$. When compared with $5 \%$ porosity the young's modulus drops to 279GPa (Figiel, Rozmus and Smuk 2011). Hardness may have been affected the rough surface that is created during fabrication. Due to this surface, the indenter may have tested on a valley of peak and have caused values to be lower.

\subsection{Dielectric Constant}

Dielectric constantmeasurementsfor the alumina parts rangedfrom9.47to 5.65 forafrequencyrangeof $20 \mathrm{~Hz}$ to $1 \mathrm{MHz}$. Dielectriclossstayed constant with all parts averaging about $2.4 \times 10^{-}$ ${ }^{3}$. These lowdielectricconstant $(\varepsilon)$ andlowdielectricloss characteristics can be beneficial for applications in radio-frequency (Alford and Penn 1996).Figure 9 is dielectric property spectra of a sample tested after fabrication.

\section{Conclusions}

With the use of binder jetting technology, the fabrication of alumina parts was achieved. By alteratingparameters such as layer thickness, particle size, and sintering profile, high density parts were achieved with $96 \%$ relative density. The increase in powder distribution and smaller layer thickness provided the best results. By increasing sintering time, a much desirable density and compression strength was achieved. Further characterization must be conducted to fully understand how alumina fabricated using binder-jetting technology may perform in certain applications. Due to the capacities of alumina and that of additive manufacturing, complex components are achieved for such applications of sensor housing. The ability to fabricated high dense parts could provide the needed protection to sensors in harsh environments. Other structure that may not be achievable with traditional fabrication processes, such and mesh and foam structures, could be achieved thus allowing the opportunity for medical applications.

\section{Acknowledgment}

The research was performed and completed at The University of Texas at El Paso (UTEP), in the W.M. Keck Center for 3D Innovation, where the facilities are larger than 13,000 sq. ft. and provide access to state of the art equipment as a result of funding from the State of Texas Emerging Technology Fund. The research was supported by the U.S. Department of Energy (DOE), award No. DE-FE0012321. Funding for students was provided in part by the ExOne Company. Any findings, opinions, conclusions, or suggestions herein are those of the authors, and do not necessarily reflect the views of the DOE or the ExOne Company.

\section{References}

n.d.

Agarwala, M. K., R. V. Weeren, A. Bandyopadhyay, P. J. Whalen, A. Safari, and S. C. Danforth. "Fused Deposition of Ceramics and Metals: An Overview." Solid Freeform Fabrication Symposium. 1996. 385-392. 
Aguilera, E., Ramos, J., Espalin, D., Cedillos, F., Muse, D., Wicker, R., and MacDonald, E. "3D Printing of Electro Mechanical Systems." In Proceedings of 2013 Annual International Solid Freeform Fabrication Symposium. Austin, TX, 2013.

Alford, Neil M, and Stuart J Penn. "Sintered Alumina with low Dielectric Loss." Journal of Applied Physics, 1996: 5895-5898.

Allahverdi, M., S. C. Danforth, M. Jafari, and A. Safari. "Processing of advanced electroceramic components by fused deposition technique." Journal of the European Ceramic Society, 2001: 1485-1490.

"ASTM International, 2012, ASTM Standard F2792-12a, "Standard Terminology for Additive Manufacturing Technologies"." n.d.

Balla, V. K., S. Bose, and A. Bandyopadhyay. "Processing of Bulk Alumina Ceramics Using Laser Engineered Net Shaping." Applied Ceramic Technology, 2008: 234-242.

Bertrand, Ph., F. Bayle, C. Combe, P. Goeuriot, and I. Smurov. "Ceramic components manufacturing by selective laser sintering." Applied Surface Science, 2007: 989-992.

Biasini, V., M. Parasporo, and A. Bellosi. "Fabrication and characterisation of A12O3 porous bodies by hot isostatic pressing." Thin Solid Films, 1997: 207-211.

Chang, Pei-Ling, Yu-Chun Wu, Ssu-Jung Lai, and Fu-Su Yen. "Size effects on $\mathrm{x}$ - to alpha -A12O3 phase transformation ." ScienceDirect, 2009: 1-8.

Chen, L. Y., G. W. Hunter, P. G. Neudeck, G. M. Beheim, D. J. Spry, and R. D. Meredith. "Packaging Technologies for High Temperature Electronics and Sensors." 59th ISA International Instrumentation Symposium. Proceedings of MFPT 2013/ISA's 29th IIS, 2013.

Cheng, B., S. Price, J. Lydon, K. Cooper, and K. Chou. "On Process Temperature in Powder-Bed Electron Beam Additive Manufacturing: Model Development and Validation." Journal of Manufacturing Science and Engineering, 2014: 1-12.

Christensen, A., Kircher, R., and Lippincott, A. "Qualification of Electron Beam Melted (EBM) Ti-6Al4V-ELI for Orthopaedic Applications." In Medical Device Materials IV: Proceedings of the Materials and Processes for Medical Devices Conference. Palm Desert, California, 2007.

Cullity, B D. Element of X-Ray Diffraction . Addison-Wesley Publishing Company, Inc., 1976.

D, Brandon, and W Kaplan. "Microstructural Characterization of Materials." 74. 1999.

Dcosta, D. J., and W. Sun. "Freeform Fabrication of Ti3SiC2 Structures." Solid Freeform Fabrication Symposium. Austin, 2001.

Dinwiddie, R. B., R. R. Dehoff, P. D. Lloyd, L. E. Lowe, and J. B. Ulrich. "Thermographic In-Situ Process monitoring of the Electron Beam Melting Technology used in Additive Manufacturing." Proceedings of SPIE digital library, 2013: 1-9.

Figiel , P, M Rozmus, and B Smuk. "Properties of aluimna ceramics obtained by conventional and nonconventional methods for sintering ceramics." Journal of Achievements in Materials and Manufacturing Engineering, 2011: 29-34.

Gaytan, S. M., M. Cadena, M. Aldaz, E. Herderick, F. Medina, and R. Wicker. "Analysis of ferroelectric ceramic fabricated by binder jetting technology." Solid Freeform Fabrication Symposium. Austin, TX, 2013. 859-868.

Guo, N., and Leu, M.C. "Additive Manufacturing Technology, Applications and Research Needs." Frontiers of Mechanical Engineering 8, no. 3 (2013): 215-243.

Hinczewski, C., S. Corbel, and T. Chartier. "Ceramic Suspensions Suitable for Stereolithography." Journal of the European Ceramic Society, 1998: 583-590.

Kruth, J. P., M. C. Leu, and T. Nakagawa. "Progress in Additive Manufacturing and Rapid Prototyping." Annals of the CIRP, 1998: 525-40.

Langmuir, I. "The Vapor Pressure of Metallic Tungsten." Physical Review 2, no. 5 (1913): 329-342.

Lescher, F., H. Camblong, O. Curea, and R. Briand. "LPV Control of Wind Turbines for Fatigue Loads Reduction using Intelligent Micro Sensors." In Proceedings of the 2007 American Control Conference. New York City, USA, July 11-13, 2007. 
Leu, M. C., S. Pattnaik, and G. E. Hilmas. "Optimization of Selective Laser Sintering Process for Fabrication of Zirconium Diboride Parts." Solid Freeform Fabrication Symposium. Austin, 2010. 493-503.

Lewis, J. A. "Direct-write assembly of ceramics from colloidal inks." Current Opinion in Solid State and Materials Science, 2002: 245-250.

Li, X., C., Prinz, F., and Seim, J. "Thermal Behavior of a Metal Embedded Fiber Bragg Grating Sensor." Smart Materials and Structures 10, no. 4 (2001): 575-579.

Li, X., Glonas, A., and Prinz, F.B. "Shape Deposition Manufacturing of Smart Metallic Structures with embedded sensors." In SPIE's 7th Annual International Symposium on Smart Structures and Materials. 2000.

Medvedovski, E. "Alumina-mullite ceramics for structural applications." Ceramics International 32, 2006: 369-375.

Medvedovski, E. "Ballistic performance of armour ceramics: Influence of design and structure. Part I." Ceramics International 36, 2010: 2103-2115.

Meethong, N., J. Sirirot, and S. Srilomsak. "Statistical Analysis of Composition and Temperature for Alumina Crucible Fabrication." Suranaree Journal of Science and Technology, 2013: 317-327.

Murr, L., E., Esquivel, E., V., Quinones, S., A., Gaytan, S., M., Lopez, M., I., Martinez, E., Y., Medina, F., Hernandez, D., H., Martinez, E., Martinez, J., L., Stafford, S., W., Brown, D., K., Hoppe, T., Meyers, W., Lindhe, U., and Wicker, R., B. "Microstructure and Mechanical Properties of Electron Beam-rapid Manufactured Ti-6Al-4V Bimedical Pototypes Compared to Wrought Ti6Al-4V." Materials Characterization 60, no. 2 (2009): 96-105.

NASA. Fabrication Method Produces High-Grade Alumina Crucibles. NASA Tech Brief 65-10078, Virginia: NASA, 1965.

Pille, D., C.,. "In-Process Embedding of Piezo Sensors and RFID Transponders into Cast Parts for Autonomous Manufacturing Logistics ." Smart Systems Integration. Como, Italy, 2010.

Prewitt, A., D. Effects of the Poling Process on Dielectric, Piezoelectric, and Ferroelectric Properties of Lad Ziconate. Proquest Dissertations and Theses, Thesis (Ph.D), University of Plorida, 2012.

Rai, R., Campbell, M., and Wood, K. "Extracting Product Performance by Embedding Sensors in SFF Prototypes." In Proceedings of International Solid Freeform Fabrication Symposium. Austin, Texas, 2004.

Rodriguez, E., et al. "Integration of a Thermal Imaging Feedback Control System in Electron Beam Melting." Solid Freeform Fabrication Symposium. Austin: SFF proceedings archive, 2012. 945961.

Scharowsky, T., F. Osmanlic, R. F. Singer, and C. Korner. "Melt pool dynamics during selective electron beam melting." Applied Physics A, 2014: 1303-1307.

Sirohi, J., and Chopra, I. "Fundamental understanding of piezoelectric strain sensors." Journal of Intelligent Material Systems and Structures 11, no. 4 (2000): 246-257.

Sprague, J. L. "Multilayer Ceramic Packaging Alternatives." IEEE transactions on components, hybrids, and manufacturing technology, 1990: 390-396.

Sun, W., D. J. Dcosta, F. Lin, and T. El-Raghy. "Freeform fabrication of Ti3SiC2 powder-based structures Part I-Integrated fabrication process." Materials Processing Technology, 2002: 343351.

Tan, Q., et al. "A High Temperature Capacitive Pressure Sensor Based on Alumna Ceramic for in Situ Measurement at 600C." Sensors, 2014: 2417-2430.

Terrazas, C., A., Gaytan, S., M., Rodriguez, E., Espalin, D., Murr, L.E., Medina, F., and Wicker, R., B. "Multi-material Metallic Structure Fabrication using Electron Beam Melting." The International Journal of Advanced Manufacturing Technology 71, no. 1-4 (2014): 33-45.

Vives, A. A. Piezoelectric Transducers and Applications. New York: Springer, 2008.

Vives, A., A. Piezoelectric Transducers and Applications. New York: Springer, 2008.

Webster, J., G. The Measurement, Instrumentation and Sensors Handbook. A CRC Handbook Published in Cooperation with IEEE Press, 1999. 
Zhang, S., Xia, R., Lebrun, L., Anderson, D., and Shrout, T., R. "Piezoelectric Materials for High Power, High Temperature Applications." Materials Letters 59, no. 27 (2005): 3471-3475. 


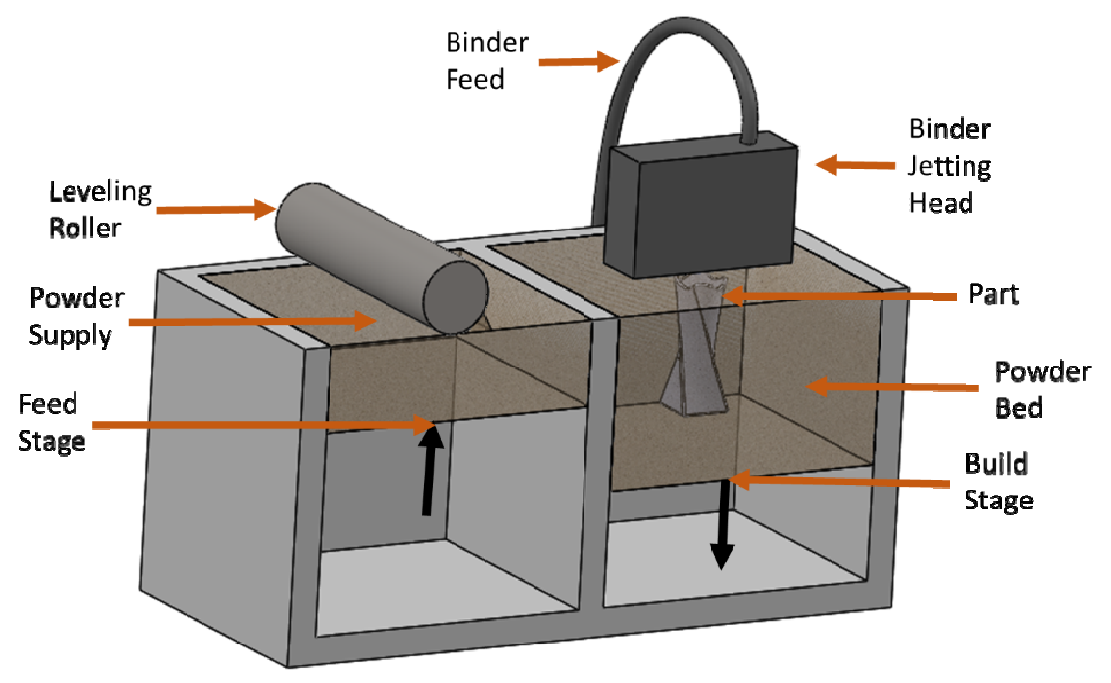

Figure 1.Schematic representing the ExOne components used for the fabrication process.

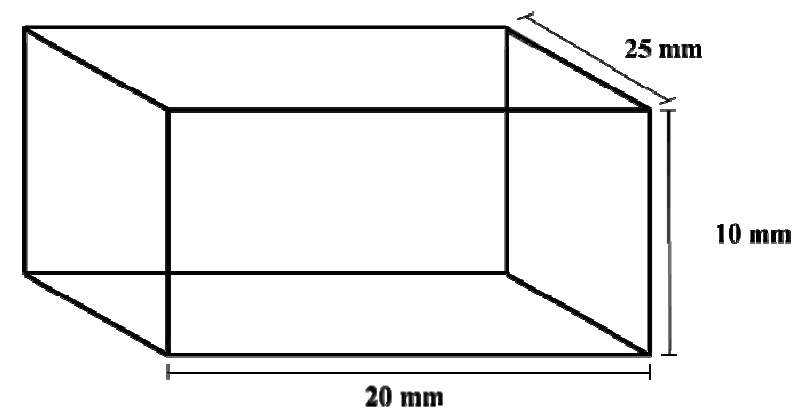

Figure 2. Original CAD file used in order to measure the shrinkage that occurs after sintering. 


\section{Green Body}

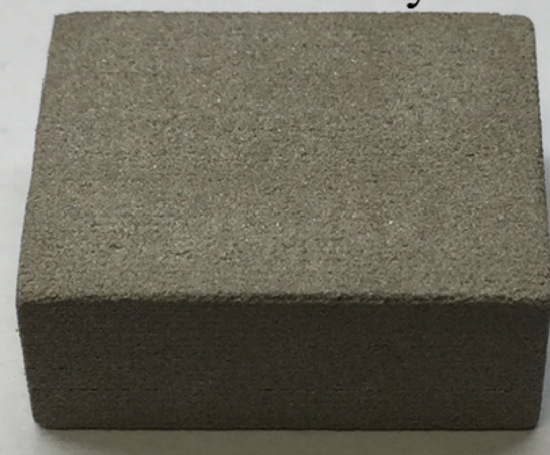

\section{Sintered Body}

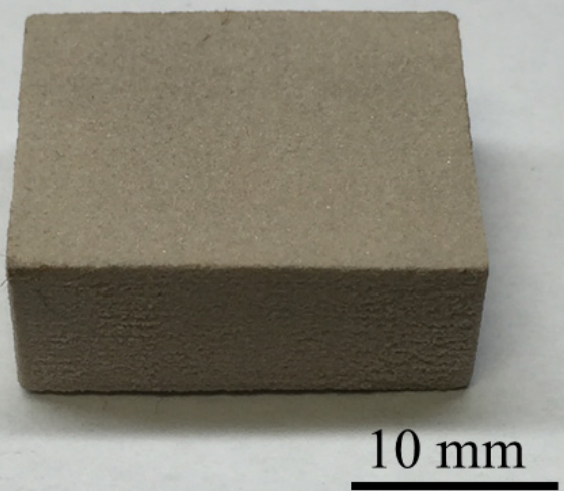

Figure 3.Green and sintered body after sintering at $1600^{\circ} \mathrm{C}$ for 16 hours.
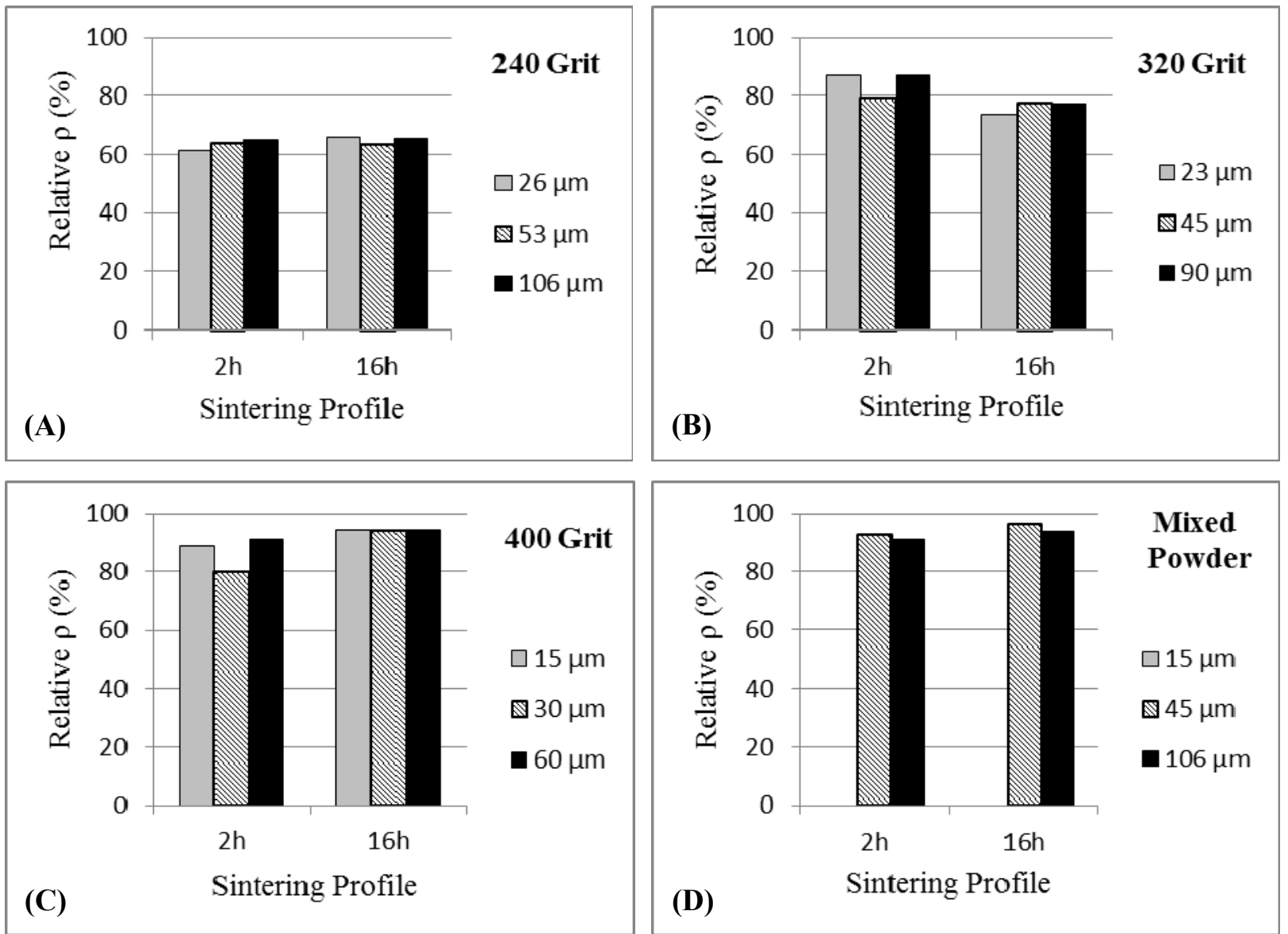

Figure 4. Relative density vs. sintering profiles including the three layer thickness used for each powder. (A) 240 grit size powder or $53 \mu \mathrm{m}$ particle size, (B) 320 powder size or $45 \mu \mathrm{m}$ particle size, (C) 400 grit size powder or $30 \mu \mathrm{m}$ particle size, (D) combination of all three powders. 


\begin{tabular}{|c|c|c|}
\hline Build Direction & Shrinkage (\%) & Standard Deviation \\
\hline X & 7.92 & 4.99 \\
\hline Y & 8.34 & 5.49 \\
\hline Z & 10.27 & 6.39 \\
\hline
\end{tabular}

Table 1.Average shrinkage occurs on samples after sintering process 

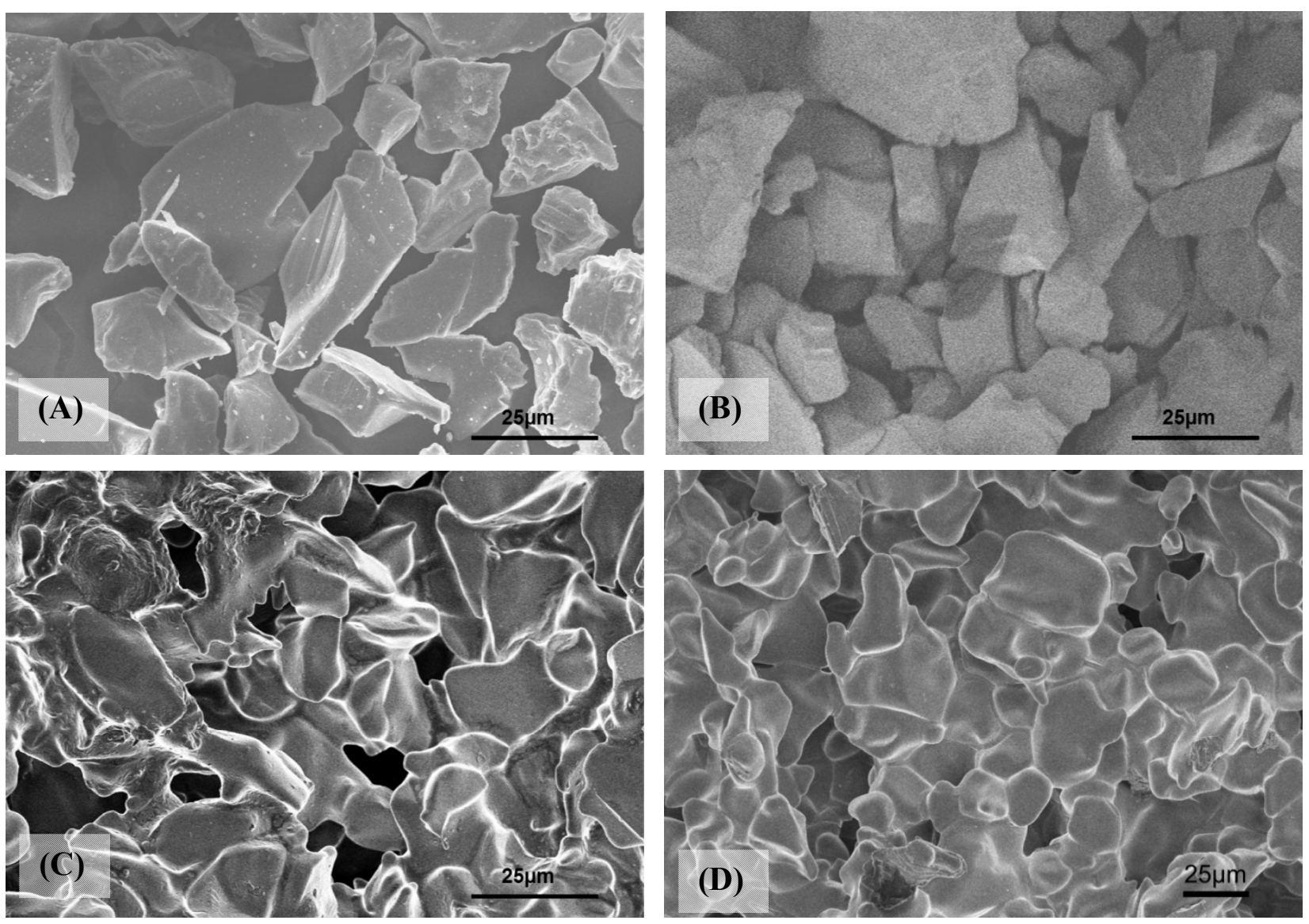

Figure 5. SEM images for (A) As-purchased powder (B) Green body fabricated part (C) Part sintered for 2 hours and (D) Part sintered for 16 hours. All parts were mixed powder at $45 \mu \mathrm{m}$ layer thinness. 


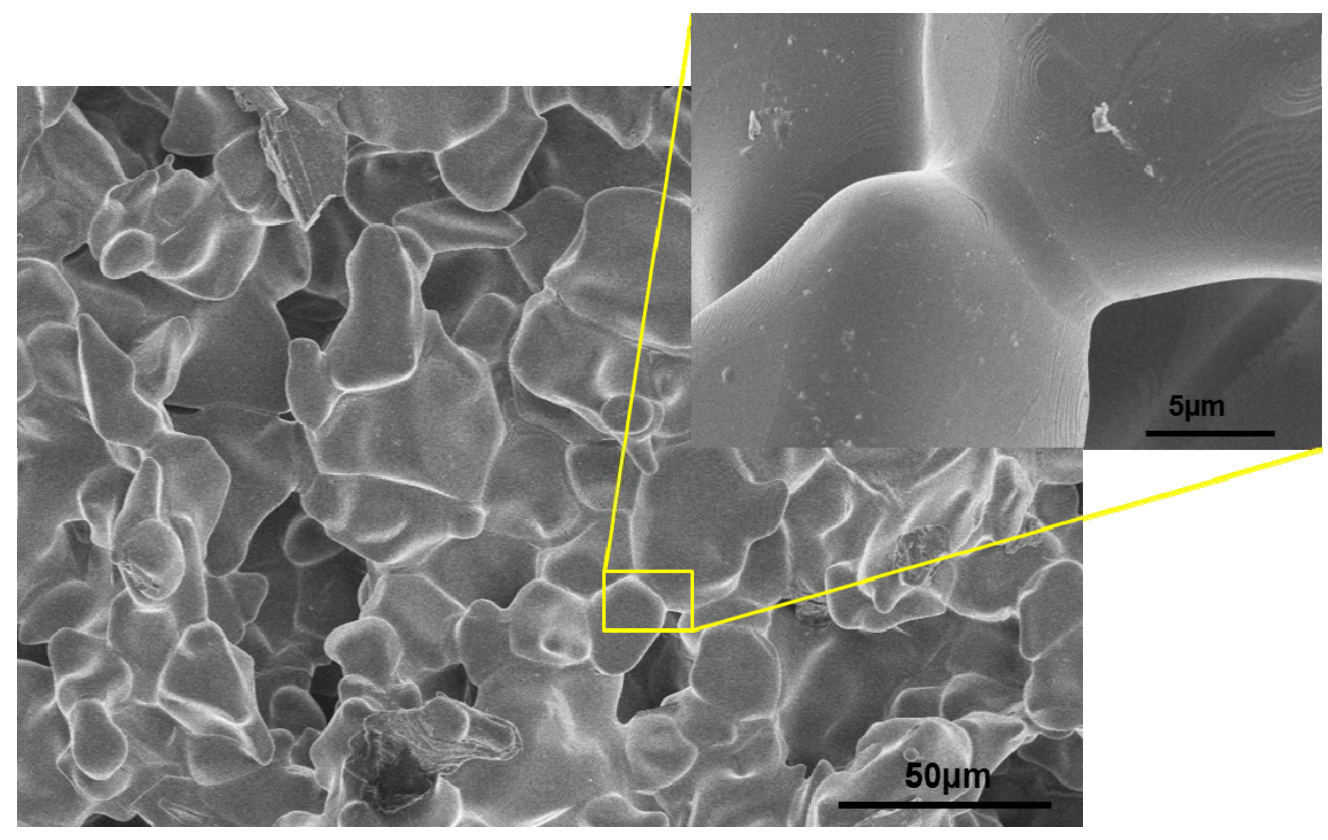

Figure 6. SEM image of 16 hour sintered part with a high-magnified image of creation of necks between two powder particles.

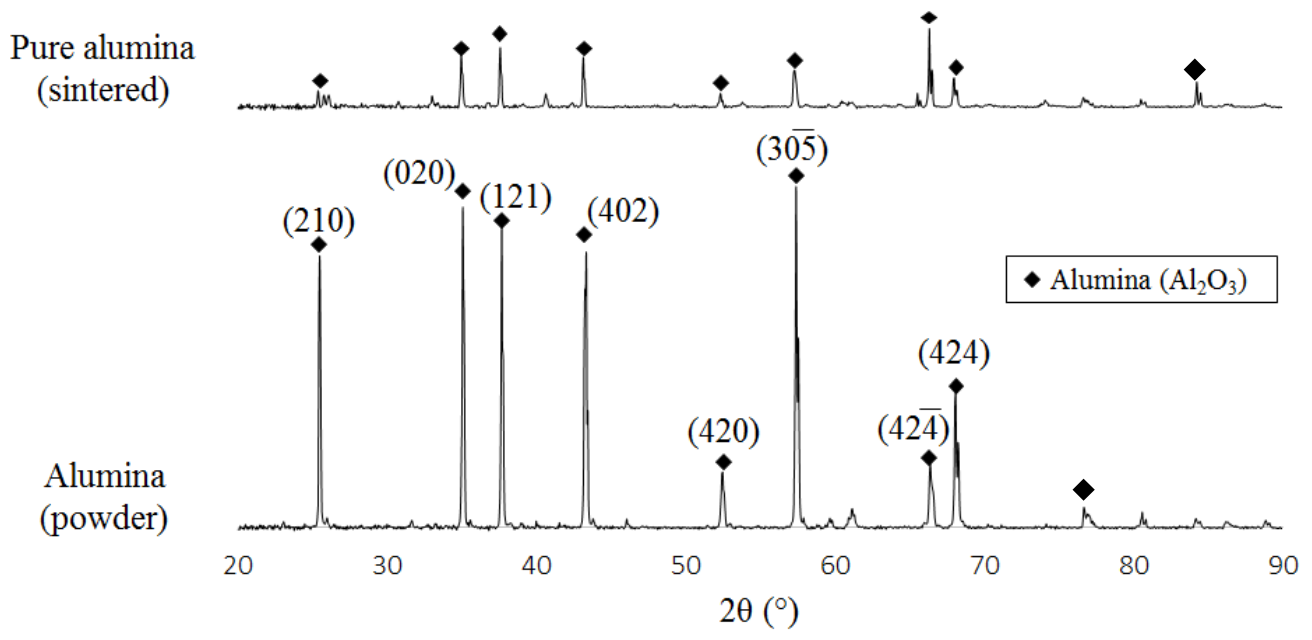

Figure 7. XRD spectra of pure alumina powder (bottom) and sintered pure alumina component (top). Matching peaks are referenced with the blue symbols 

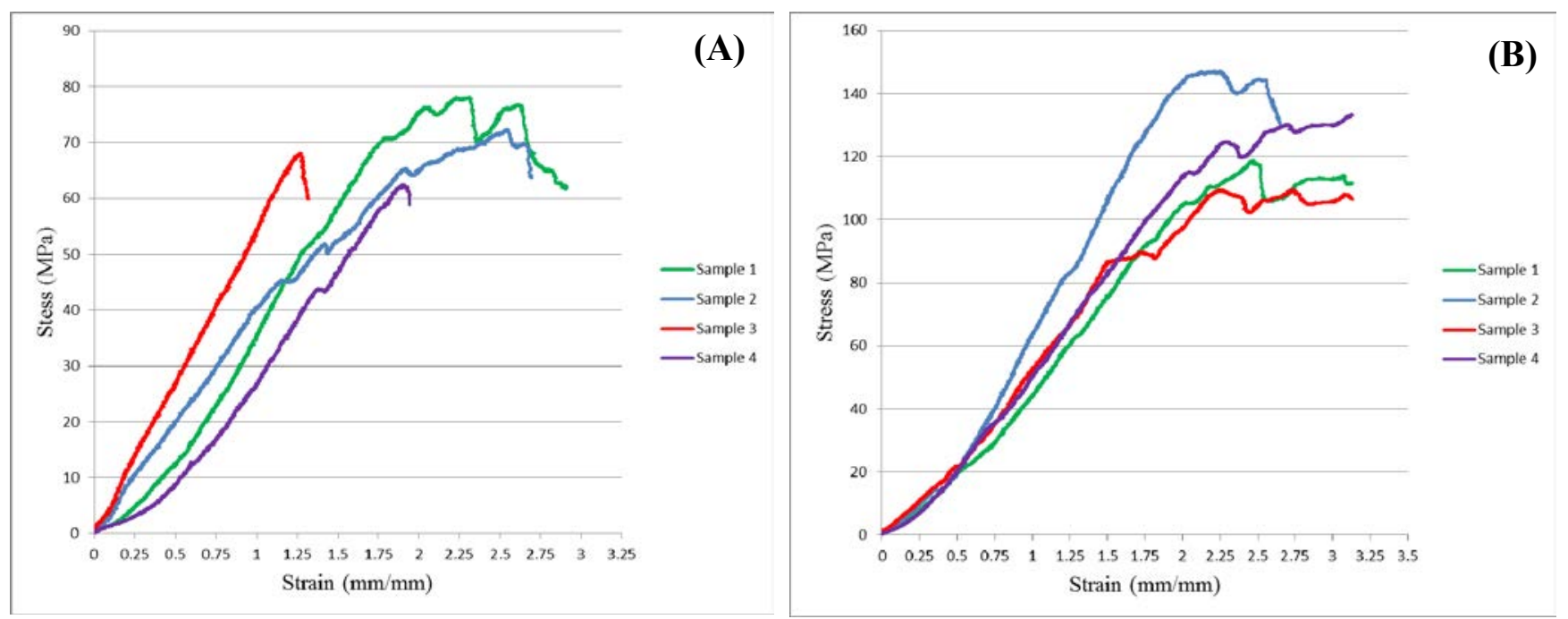

Figure 8. Stress-Strain curves of the alumina compression test. (A) Samples that were sintered for 2 hours and (B) Samples that were sintered at 16 hours.

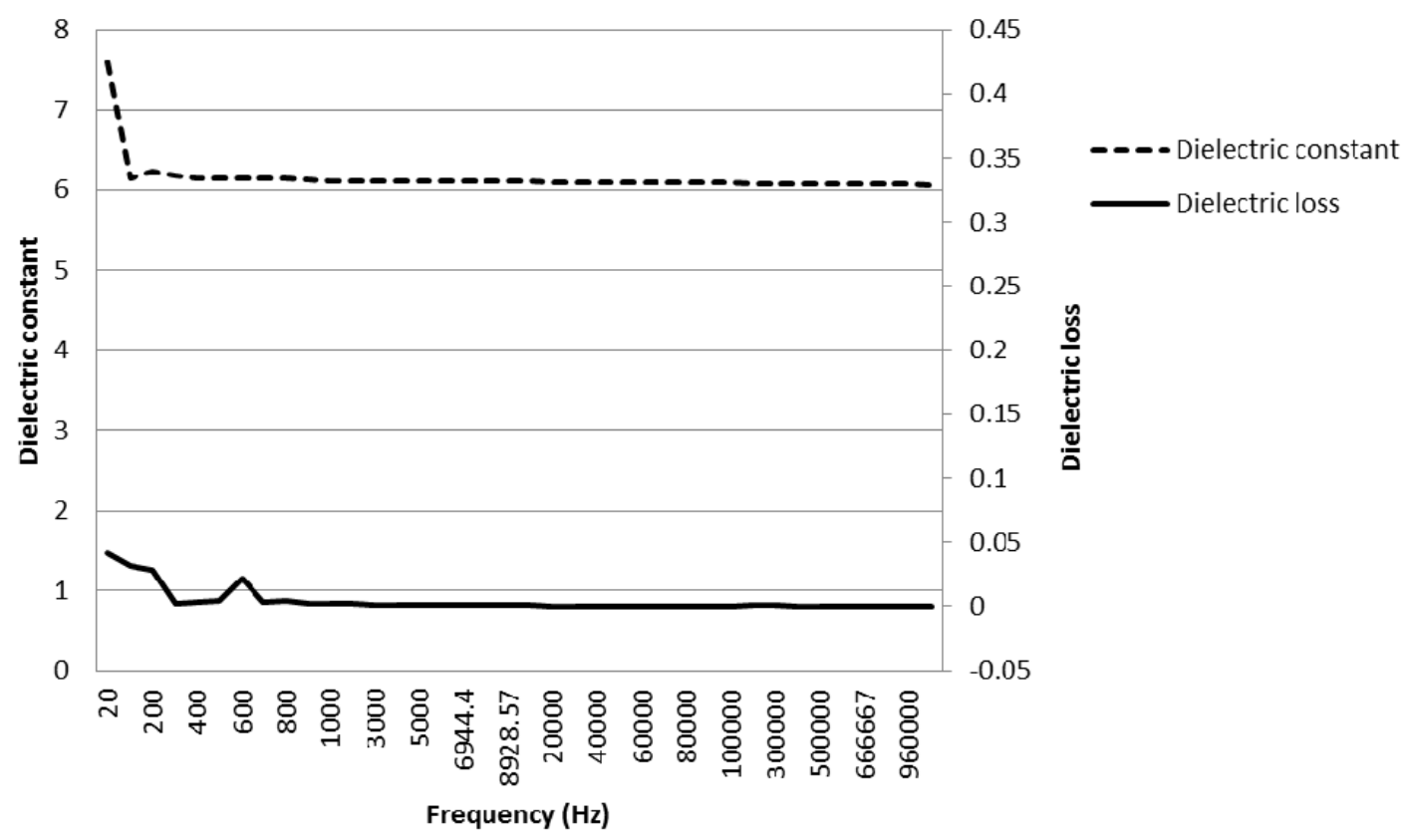

Figure 9. Dielectric constant and dielectric loss for alumina fabricated by binder jetting technology 